\title{
Capacidade combinatória de linhagens de milho avaliada por meio de testadores adaptados à safrinha
}

\author{
Edson Bolson ${ }^{1}$, Carlos Alberto Scapim², Luiz Rafael Clovis ${ }^{3}$, Antonio Teixeira do Amaral Junior ${ }^{4}$, \\ Ismael Lourenço de Jesus Freitas ${ }^{5}$
}

10.1590/0034-737X201663040009

\section{RESUMO}

O objetivo deste trabalho foi estimar a capacidade de combinação de 47 linhagens de milho desenvolvidas pela Universidade Estadual de Maringá, no sentido de identificar as linhagens mais promissoras para utilização em programas de melhoramento voltados para safrinha. Para isso, as linhagens foram cruzadas em topcrosses com dois híbridos comerciais adaptados à safrinha (P30K75 e AG9010), utilizados como testadores de base genética estreita. Os topcrosses foram avaliados em experimentos delineados em blocos completos ao acaso, com duas repetições, e alocados em quatro locais representativos para a safrinha, nos estados do Paraná, São Paulo e Mato Grosso do Sul. Adicionalmente, as linhagens per se foram avaliadas em um experimento em Floresta, PR. Foram avaliados os caracteres: (i) rendimento de grãos, em kg ha-1 ; (ii) florescimento feminino e masculino; (iii) tolerância ao estresse hídrico. Para as linhagens per se, os quadrados médios foram significativos $(\mathrm{p}<0,05)$ para rendimento de grãos e florescimento. As capacidades gerais para testadores e linhagens e, específica de combinação entre linhagens e testadores, foram significativas $(\mathrm{p}<0,05)$ para todas as características avaliadas. A linhagem 21 destacou-se pela alta capacidade geral de combinação $\left(\hat{g}_{i}\right)$ para rendimento de grãos, nos quatro ambientes. Nas linhagens 4, 37, 38, 39 e 47 constataram-serelevantes para rendimento de grãos, em dois ambientes, inclusive sob condições de estresse hídrico, e para florescimento. As combinações AG9010 $\mathrm{x}$ linhagem 37 e P30K75 x linhagem 18 tiveram destaque e as linhagens 18 e 37 foram indicadas como testadoras de novas linhagens oriundas dos testadores.

Palavras-chave: Zea mays; rendimento de grãos; segunda safra; topcrosses.

\section{ABSTRACT}

\section{Combining ability of maize inbred lines evaluated by testers adapted to the second crop}

The objective of this study was to estimate the combining ability of 47 maize inbred lines, developed by the Maringá State University, in order to identify the most promising ones regarding maize breeding programs focused on the second crop. For this, the lines were crossed in topcross scheme with two hybrids adapted to second crop (P30K75 and AG9010), used as narrow genetic base testers. The topcrosses were evaluated in randomized block design, with two repetitions, in four key-locations for the second crop along the states of Paraná, São Paulo and Mato Grosso do Sul. In addition, the lines per se were evaluated in Floresta-PR. The following traits were evaluated: (i) grain yield, in kg $\mathrm{ha}^{-1}$; (ii) male and female flowering; and (iii) tolerance to drought stress. For the inbred lines per se, the mean squares were significant $(\mathrm{p}<0.05)$ for both grain yield and flowering. The general combining ability of testers and lines and the

\footnotetext{
Submetido em 01/04/2014 e aprovado em 10/12/2015

${ }^{1}$ Monsanto do Brasil Ltda, Departamento de Pesquisa de Milho Híbrido voltado para safrinha, Rolandia, Paraná, Brasil. edson.bolson@yahoo.com.br ${ }^{2}$ Universidade Estadual de Maringá, Centro de Ciências Agrárias, Departamento de Agronomia, Maringá, Paraná, Brasil. cascapim@uem.br

${ }^{3}$ Universidade Estadual de Maringá, Centro de Ciências Agrárias, Departamento de Agronomia, Maringá, Paraná, Brasil. luizrafaelclovis@hotmail.com

${ }^{4}$ Universidade Estadual do Norte Fluminense Darcy Ribeiro, Laboratório de Melhoramento Genético Vegetal, Campos dos Goytacazes, Rio de Janeiro, Brasil. amaraljr@pq.cnpq.br 5 Universidade Estadual do Norte Fluminense Darcy Ribeiro, Laboratório de Melhoramento Genético Vegetal, Campos dos Goytacazes, Rio de Janeiro, Brasil. ismaelljf@yahoo.com.br *Autor para correspondência: ismaelljf@yahoo.com.br
} 
specific combining ability between testers and lines were significant $(\mathrm{p}<0.05)$ for all traits. The line 21 stood out because of the high general combining ability along the four environments. Among the lines 4, 37, 38, 39 and 47, relevant general combining ability effects $\left(\hat{g}_{i}\right)$ were verified for grain yield at least in two environments, including drought stress environment and flowering. The combinations AG9010 × Line 37 and P30K75 × Line 18 stood out, and lines 18 and 37 were indicated as testers for new lines coming from the testers.

Key words: Zea mays; grain yield; second crop; topcrosses.

\section{INTRODUÇÃO}

O cultivo do milho (Zea mays L.) na safrinha tem sido viável economicamente para o produtor (Casagrande \& Fornasieri Filho 2002). Além do retorno financeiro, a safrinha proporciona os benefícios agronômicos da rotação de culturas, como o aumento da palhada, fundamental para a manutenção do sistema de plantio direto; o controle de pragas e doenças da lavoura de verão; contribui para manter o equilíbrio dos nutrientes no solo; aumenta a sua fertilidade e permite melhor utilização dos insumos agrícolas (Souza \& Soratto 2006).

A safrinha é cultivada comercialmente em pelo menos dez estados brasileiros, destacando-se o Paraná, São Paulo, Goiás, Mato Grosso, Mato Grosso do Sul e Minas Gerais. Essa dimensão é igualmente proporcional aos desafios particulares de ambiente típico da safrinha, como risco de geadas, o déficit hídrico e a diminuição do fotoperíodo. Segundo Penariol et al., (2010), a produção por área pode ficar comprometida se a deficiência hídrica coincidir com o período do florescimento, como também na safra de verão, fase que determina a quantidade de óvulos a serem fecundados e, por consequência, a produção de grãos. Frente a esse cenário, fica evidente a importância de programas de melhoramento voltados exclusivamente à seleção de linhagens e de híbridos adaptados ao cultivo na safrinha, visando a obter materiais produtivos, responsivos, precoces, com menor porte, grãos com rápida perda de água, resistentes a pragas e doenças e menos afetados por regime de chuvas e limitações de radiação solar e de temperatura.

No nível fisiológico, o estresse hídrico acarreta diminuição da atividade fotossintética, reduzindo a eficiência de conversão da radiação interceptada em biomassa. Há observações de que o melhoramento para tolerância à seca, em populações tropicais, altera a partição de fotoassimilados, privilegiando o desenvolvimento da espiga (Mugo et al. 2003). Observa-se, também, mais rápido crescimento das espigas e do estilo-estigma e maior sincronismo entre os florescimentos masculino e feminino.

Desde sua concepção (Davis 1927), os cruzamentos topcrosses, definidos pela combinação de um ou mais genótipos testadores com uma série de linhagens ou pro- gênies a serem avaliadas, têm sido amplamente utilizados no decorrer das diferentes décadas do melhoramento de milho. Esses cruzamentos são avaliados estatisticamente como dialelos parciais (Geraldi \& Miranda Filho 1988) e têm sua principal aplicação voltada ao conhecimento da capacidade combinatória de linhagens ou progênies. Não há muitos relatos do estudo da capacidade de combinação de linhagens de milho, necessariamente realizados sob condições de safrinha e por meio de testadores desenvolvidos e adaptados à safrinha.

O melhoramento genético do milho para a obtenção de híbridos envolve várias etapas que demandam tempo e recurso (Silveira \& Moro 2009). Segundo Amorim \& Souza (2005), a escolha das populações para obtenção dessas linhagens é uma das fases mais importantes para o sucesso do programa. A utilização de híbridos comerciais como fonte de novas linhagens, denominadas linhagens de segundo ciclo, está-se tornando uma prática comum entre os melhoristas (Bison et al. 2003), por apresentarem alta produtividade e grande proporção de locos favoráveis já fixados.

Até o momento, a maioria dos cultivares utilizados não foi desenvolvida para o cultivo de milho safrinha, sendo, na realidade, para a safra primavera-verão e apenas testada na safrinha, ou seja, no outono-inverno (Kvitschal et al., 2004).

Com a proposta de estimar a capacidade de combinação de linhagens de milho para rendimento de grãos, florescimento e tolerância ao estresse hídrico, os topcrosses com dois híbridos adaptados à safrinha, P30K75 e AG9010, ambos de base genética estreita, foram avaliados em locais representativos para a safrinha, nos estados do Paraná, São Paulo e Mato Grosso do Sul. Posto isso, o objetivo principal deste estudo foi identificar as linhagens mais promissoras para um programa de desenvolvimento de híbridos para a safrinha.

\section{MATERIAL E MÉTODOS}

Foram utilizadas neste estudo (Tabela 1) 47 linhagens $\mathrm{S}_{6}$ de milho, desenvolvidas pela Universidade Estadual de Maringá, Paraná. Essas linhagens foram cruzadas com dois híbridos simples modificados (P30K75/Pioneer e AG9010/ 
Agroceres), utilizados como testadores. Estes testadores foram eleitos, considerando-se suas altas estabilidades e adaptabilidades aos cultivos de safrinha e ampla aceitação no mercado. Com bom desempenho, o híbrido AG9010 conta ainda com precocidade e alta resistência aos estresses intrínsecos da safrinha. Já o híbrido P30K75 foi escolhido por apresentar boa estabilidade e tolerância à Cercospora spp. e Puccinia polysora.

Os híbridos topcrosses, entre os testadores P30K75 e AG9010 com as linhagens, foram obtidos por meio de lotes isolados de despendoamento, instalados a campo na Fazenda Experimental de Iguatemi, pertencente à Universidade Estadual de Maringá.

Para permitir o tipo de análise estatística desejada, os topcrosses com cada testador foram avaliados em experimentos independentes. Nos experimentos referentes aos topcrosses com o testador P30K75, foram avaliados 48 tratamentos, os quais consistiram em seus 47 híbridos topcrosses e o próprio híbrido, utilizado como testador. Para os experimentos dos topcrosses com o testador AG9010, seus 47 híbridos topcrosses foram avaliados juntamente com o referido testador. Desta forma, cada experimento contou com 48 entradas, casualizadas conforme o delineamento experimental de blocos completos, com duas repetições. Tanto os experimentos referentes aos topcrosses com P30K75 quanto aos topcrosses com AG9010 foram instalados em quatro diferentes locais, dotados de diferentes características edafoclimáticas e representativos das principais regiões de cultivo do milho safrinha nos estados do Paraná, São Paulo e Mato Grosso do Sul, a saber: Floresta, PR, São Miguel do Iguaçu, PR, Ibirarema-SP e Rio Brilhante, MS. Adicionalmente, para a avaliação per se das linhagens, em Floresta, PR foi instalado um experimento em blocos completos, com tratamentos ao acaso, com duas repetições. Nesse caso, os tratamentos consistiram em 47 linhagens avaliadas neste estudo. Em todos os experimentos, as parcelas experimentais consistiram em duas linhas de semeadura de 5,0 m, espaçadas em 0,80 m entre si.

As avaliações dos experimentos contemplaram as seguintes características: (i) rendimento de grãos: obtido pela aferição da massa de grãos produzidos em cada parcela, realizada em colheitadeira adaptada aos experimentos e com balança de precisão e determinador de umidade. Para cada parcela, os dados foram corrigidos para o estande de 50 plantas por parcela e para a umidade de $14,5 \%$; (ii) florescimentos feminino e masculino: foram anotadas as datas, em número de dias após o plantio, em que 50\% das plantas da parcela emitiram estilo-estigma de, no mínimo, quatro $\mathrm{cm}$; procedimento semelhante foi realizado quanto à liberação de pólen nos pendões; (iii) tolerância ao estresse hídrico: foram atribuídas notas de 1 a 5, seguindo-se o modelo proposto por Banziger et al. (2000), quando os

Tabela 1: Origem das linhagens utilizadas nos topcrosses

\begin{tabular}{|c|c|c|c|c|c|}
\hline $\begin{array}{l}\text { Denominação } \\
\text { das linhagens }\end{array}$ & $\begin{array}{c}\text { Origem } \\
\text { Genética }\end{array}$ & $\begin{array}{c}\text { Tipo } \\
\text { de Híbrido }\end{array}$ & Denominação & $\begin{array}{c}\text { Origem } \\
\text { Genética }\end{array}$ & $\begin{array}{c}\text { Tipo deHíbrido } \\
\text { das linhagens }\end{array}$ \\
\hline 7-H3.1 & AG8088/Agroceres & Simples & $54-\mathrm{H} 20.3$ & Tork/Syngenta & Simples \\
\hline 8-H3.2 & AG8088/Agroceres & Simples & $55-\mathrm{H} 20.3$ & Tork/Syngenta & Simples \\
\hline 11-H5.2 & Avant/Syngenta & Simples & $57-\mathrm{H} 21.1$ & AG9090/Agroceres & Simples \\
\hline 18-H9.1 & DKB350/Dekalb & Triplo & $59-\mathrm{H} 23.1$ & $\mathrm{~A} 2560$ & Simples \\
\hline 19-H9.1 & DKB350/Dekalb & Triplo & $60-\mathrm{H} 23.1$ & A2560 & Simples \\
\hline 20-H11.1 & Flash/Syngenta & Simples & $62-\mathrm{H} 23.2$ & A2560 & Simples \\
\hline 21-H11.1 & Flash/Syngenta & Simples & $63-\mathrm{H} 23.2$ & A2560 & Simples \\
\hline 22-H11.1 & Flash/Syngenta & Simples & $64-\mathrm{H} 23.2$ & A2560 & Simples \\
\hline 24-H12.2 & AG6018/Agroceres & Triplo & $67-\mathrm{H} 25.1$ & Strike/Syngenta & Simples \\
\hline 29-H13.3 & Premium/Syngenta & Simples & 69-H26.1 & 30F33/Pioneer & Simples \\
\hline 34-H17.1 & DKB747/Dekalb & Duplo & 71-H26.2 & 30F33/Pioneer & Simples \\
\hline 35-H17.1 & DKB747/Dekalb & Duplo & 73-H28.1 & DKB440/Dekalb & Simples \\
\hline 36-H17.2 & DKB747/Dekalb & Duplo & $75-\mathrm{H} 29.2$ & 30F98/Pioneer & Simples \\
\hline 37-H17.2 & DKB747/Dekalb & Duplo & 79-H31.1 & DAS422/Dow Agr. & Simples \\
\hline 39-H17.3 & DKB747/Dekalb & Duplo & 83-H33.1 & Speed//Syngenta & Simples \\
\hline 40-H17.3 & DKB747/Dekalb & Duplo & 84-H6.1 & Fort//Syngenta & Simples \\
\hline 41-H17.3 & DKB747/Dekalb & Duplo & $85-\mathrm{H} 6.2$ & Fort/Syngenta & Simples \\
\hline 42-H17.4 & DKB747/Dekalb & Duplo & 86-H6.3 & Fort/Syngenta & Simples \\
\hline 43-H17.4 & DKB747/Dekalb & Duplo & 87-H6.4 & Fort/Syngenta & Simples \\
\hline 44-H17.4 & DKB747/Dekalb & Duplo & 91-H4.4 & CD303/Coodetec & Simples \\
\hline 46-H17.5 & DKB747/Dekalb & Duplo & 93-H34.2 & DAS2C599/Dow Agr. & Simples \\
\hline 50-H17.6 & DKB747/Dekalb & Duplo & 94-H34.3 & DAS2C599/Dow Agr. & Simples \\
\hline $51-\mathrm{H} 20.1$ & Tork/Syngenta & Simples & $96-\mathrm{H}-34.5$ & DAS2C599/Dow Agr. & Simples \\
\hline $52-\mathrm{H} 20.2$ & Tork/Syngenta & Simples & & & \\
\hline
\end{tabular}

Rev. Ceres, Viçosa, v. 63, n.4, p. 492-501, jul/ago, 2016 
experimentos estavam no estádio fenológicos entre $\mathrm{R}_{3} \mathrm{e}$ $\mathrm{R}_{4}$, sendo que as notas menores referiram-se a genótipos com melhor aparência sob as condições de estresse (não havendo chuva neste período).

As avaliações de rendimento de grãos foram procedidas em todos os locais, para topcrosses e para as linhagens per se. As avaliações de florescimento deram-se em Floresta, PR, por não apresentarem, quanto a esta variável resposta, variação com o local para justificar a necessidade de outros. As notas de tolerância ao estresse hídrico foram atribuídas no experimento de Ibirarema, SP, por ser, dentre os estudados, o local que condiciona estresse hídrico, pela falta de chuva nesse período. Nesse ambiente, não foram registradas precipitações aos 28 dias antecedentes à avaliação de tolerância, permitindo essas inferências (Tabela 2).

Quanto à análise estatística e genética dos dados, inicialmente, os testes de Levene (1960) e KolmogorovSmirnov (1933) foram aplicados para examinar, respectivamente, as condições de homogeneidade de variâncias e a normalidade dos erros. Uma vez que esses pressupostos foram atendidos integralmente, as análises de variância foram procedidas individualmente (considerando-se todos os componentes do modelo de efeito aleatório, exceto a média) para os experimentos dos topcrosses de cada testador e para o experimento das linhagens per se, conforme o seguinte modelo: $Y_{i j}=\mu+g_{i}+b_{j}+e_{i j}$, em que: $Y_{i j}$ : valor observado do i-ésimo tratamento, no j-ésimo bloco; $\mu$ : média geral do experimento; $g_{i}$ : efeito do i-ésimo genótipo; $b_{j}$ : efeito do j-ésimo bloco; $e_{i j}$ : erro experimental associado à observação $Y_{i j}$.

Após isso, verificada a homogeneidade entre as variâncias residuais dos experimentos, para cada testador, foi realizada ainda a análise de variância conjunta para o rendimento de grãos. Na sequência, as estimativas de componentes de variância deram-se por meio das esperanças de quadrados médios dos modelos utilizados para a análise de variância: a) Componente de variância genética (individual), b) Componente de variância genética (conjunta), c) Componente de variância da interação genótipos $\times$ ambientes, d) Componente de variância residual, e) Herdabilidade média (sentido amplo), f) Coeficiente de variância genética $(\mathrm{CVg}), \mathrm{g})$ Coeficiente de variação experimental (CVe), h) Relação entre os coeficientes de variação genética e experimental $(\mathrm{CVg} / \mathrm{CVe})$.

$\mathrm{Na}$ sequência, as médias dos topcrosses com ambos os testadores e as estimativas de quadrado médio das análises individuais de variância foram utilizadas para as análises dialélicas, conforme o modelo proposto por Griffing (1956) e adaptado aos cruzamentos dialélicos parciais por Geraldi \& Miranda Filho (1988): $Y_{i j}=\mu+g_{i}+g_{j}+s_{i j}+\stackrel{\circ}{i j}_{i j}$ em que: $Y_{i j}$ : valor médio da combinação híbrida entre o i-ésimo testador e a j-ésima linhagem; $\mu$ : média geral; $g_{i}$ : efeito da capacidade geral de combinação do i-ésimo testador; $g_{j}$ : efeito da capacidade específica de combinação da j-ésima linhagem; $s_{i j:}$ efeito da capacidade específica de combinação entre i-ésimo testador e a j-ésima linhagem; $\varepsilon_{\mathrm{ij}}$, erro experimental médio.

Esse procedimento permitiu obter as estimativas das capacidades gerais de combinação de linhagens e de testadores e da capacidade específica entre linhagens e testadores. As análises dos dados foram realizadas como auxílio do Software Genes (Cruz, 2013), a 10\% de probabilidade.

\section{RESULTADOS E DISCUSSÃO}

As análises individuais de variância, para os topcrosses e para as linhagens per se, bem como as estimativas de alguns parâmetros genéticos e fenotípicos, são apresentadas nas Tabelas 3 e 4. Para ambos os testadores, verificou-se que os quadrados médios de topcrosses foram significativos ( $p<0,05)$, indicando a existência de variabilidade fenotípica, para as linhagens, quanto às características estudadas. Segundo Hallauer (1975), os testadores exercem papel fundamental na determinação da variabilidade genética dos topcrosses, de modo que essa inferência é dependente da frequência genética e do nível de dominância do testador. É possível inferir que os testadores utilizados são apropriados para a avaliação da capacidade combinatória das linhagens em relação às características estudadas (Tabela 3).

As médias de rendimento de grãos variaram entre 3.615,6 $\mathrm{kg} \mathrm{ha}^{-1}$, com o testador AG9010, em Ibirarema, SP, e 7.223,6 $\mathrm{kg} \mathrm{ha}^{-1}$, com o testador P30K75, em Floresta, PR

Tabela 2: Informações pertinentes aos locais dos experimentos com os topcrosses

\begin{tabular}{|c|c|c|c|c|c|c|c|c|}
\hline \multirow{2}{*}{ Local } & \multirow{2}{*}{$\begin{array}{c}\text { Região } \\
\text { do respectivo } \\
\text { estado }\end{array}$} & \multirow{2}{*}{$\begin{array}{c}\text { Altitude } \\
\text { no local } \\
\text { (m) }\end{array}$} & \multirow{2}{*}{$\begin{array}{c}\text { Data de } \\
\text { semeadura }\end{array}$} & \multirow{2}{*}{$\begin{array}{c}\text { Densidade } \\
\text { de semeadura } \\
(\mathrm{pl} \mathrm{ha-1)}\end{array}$} & \multicolumn{4}{|c|}{ Precipitação durante os ensaios (mm) } \\
\hline & & & & & $V_{E}-V_{3}$ & $V_{4}-V_{8}$ & $V_{9}-V_{T}$ & $R_{1}-R_{6}$ \\
\hline São Miguel do Iguaçu-PR & Oeste & 307 & $13 / 02 / 2010$ & 62,5 mil & 126 & 152 & 278 & 76 \\
\hline Floresta-PR & Centro-norte & 490 & 27/02/2010 & $62,5 \mathrm{mil}$ & 108 & 136 & 188 & 88 \\
\hline Rio Brilhante-MS & Sudoeste & 290 & $13 / 03 / 2010$ & 62,5 mil & 97 & 134 & 178 & 62 \\
\hline Ibirarema-SP & Sudoeste & 470 & $19 / 03 / 2010$ & 62,5 mil & 77 & 61 & 94 & 7 \\
\hline
\end{tabular}

$\mathbf{V}_{\mathbf{E}}$ : emergência. $\mathbf{V}_{3}$ : três folhas desenvolvidas. $\mathbf{V}_{4}$ : quatro folhas desenvolvidas. $\mathbf{V}_{8}$ : oito folhas desenvolvidas. $\mathbf{V}_{9}:$ nove folhas desenvolvidas. $\mathbf{V}_{\mathrm{T}}$ : Pendoamento. $\mathbf{R}_{\mathbf{1}}$ : Florescimento Feminino ou “embonecamento". $\mathbf{R}_{\mathbf{6}}$ : Grão em maturidade Fisiológica (55 a 65 dias após R1). 
(Tabela 3). A média de rendimento das linhagens per se foi de $3.189,76 \mathrm{ha}^{-1}$, resultado muito próximo à média nacional (Tabela 3). Apesar de os produtores estarem utilizando, ano após ano, híbridos mais adaptados à condição de safrinha, e adotando mais tecnologia em seus cultivos, o que se observa é que o sucesso do rendimento está diretamente ligado aos fatores ambientais.

$\mathrm{Na}$ avaliação das linhagens per se, verificou-se que os quadrados médios das linhagens foram significativos ( $\mathrm{p}<$ $0,05)$, indicando que há diferenças entre as linhagens para as características de rendimentos de grãos e de florescimento. Isso é importante do ponto de vista do melhoramento, sugerindo a possibilidade de seleção das linhagens promissoras e que devem continuar no programa (Tabela 4). Porém, o critério mais apropriado para a seleção das linhagens consiste em sua capacidade de combinação.

Os coeficientes de variação experimental para florescimento masculino e feminino foram relativamente baixos $(1,4$ e $1,3 \%)$, segundo as premissas propostas por
Gomes (1982) para experimentos agrícolas. De modo geral, este autor propôs que são considerados baixos CVs menores que $10 \%$. De fato, indica uma boa precisão na coleta dos dados de florescimento e na condução do experimento, atribuindo confiabilidade aos resultados. Em Floresta, PR, as médias foram de 64,1 e de 64,5 dias para, respectivamente, os florescimentos masculino e feminino para os topcrosses sintetizados com o testador P30K75 (Tabela 3). Para os topcrosses com o testador AG9010, as médias foram de 60,4 e de 60,8 dias, respectivamente, para os florescimentos masculino e feminino (Tabela 3). As linhagens per se apresentaram, respectivamente, médias de 67,41 dias para o florescimento masculino e de 68,89 dias para florescimento feminino (Tabela 4).

Os coeficientes de variação experimental para rendimento de grãos, em todos os ambientes, para ambos os testadores, apresentaram-se com valores abaixo de $13 \%$, indicando, segundo Scapim et al. (1995), que os dados são confiáveis (Tabela 3 ). As médias gerais de rendimento

Tabela 3: Análise de variância e estimativas de parâmetros genéticos e fenotípicos para as características avaliadas nos híbridos topcrosses, nos diferentes ambientes

\begin{tabular}{|c|c|c|c|c|c|c|c|c|}
\hline \multirow{4}{*}{ Fontes de variação } & \multirow{4}{*}{ GL } & \multicolumn{7}{|c|}{ Quadrados médios } \\
\hline & & \multirow{2}{*}{\multicolumn{4}{|c|}{$\begin{array}{l}\text { Rendimento de grãos } \\
\qquad\left(\mathrm{kg} \mathrm{ha}^{-1}\right)^{2}\end{array}$}} & \multirow{2}{*}{\multicolumn{3}{|c|}{$\begin{array}{r}\text { Florescimento DRTR } \\
\text { Masculino }(d)^{2} \text { Feminino }(d)^{2}\end{array}$}} \\
\hline & & & & & & & & \\
\hline & & IBI & RBR & SMI & FLO & FLO & & IBI \\
\hline \multicolumn{9}{|l|}{ Testador $1(30 \mathrm{~K} 75)$} \\
\hline Blocos & 1 & 181473,9 & 848378,5 & 803188,9 & 2177224,0 & 0,27 & 0,00 & 0,10 \\
\hline Topcrosses & 46 & $543745,5^{*}$ & $1191757,0 *$ & $1151479,2^{*}$ & $1378337,8^{*}$ & $5,87 *$ & $6,40 *$ & $3,10 *$ \\
\hline Resíduo & 46 & 136569,4 & 351956,1 & 557841,4 & 544153,1 & 0,66 & 0,72 & 0,83 \\
\hline Média & & 3681,8 & 6218,2 & 6712,1 & 7223,6 & 64,1 & 64,5 & 3,4 \\
\hline Média do Híbrido & & 5706,8 & 8674,4 & 8725,7 & 9101,3 & - & - & - \\
\hline Cve & & 10,0 & 9,5 & 11,1 & 10,2 & 1,3 & 1,3 & 27,3 \\
\hline$\hat{\sigma}^{2} f$ & & 271872,7 & 595878,5 & 575739,6 & 689168,9 & 2,93 & 3,20 & 1,55 \\
\hline$\hat{\sigma}^{2} g$ & & 203588,0 & 419900,4 & 296818,9 & 272076,5 & 2,60 & 2,84 & 1,13 \\
\hline$\hat{h}^{2}$ & & 0,75 & 0,70 & 0,52 & 0,60 & 0,89 & 0,89 & 0,73 \\
\hline $\mathrm{CVg}$ & & 12,3 & 10,4 & 8,1 & 8,9 & 2,5 & 2,6 & 31,8 \\
\hline $\mathrm{CVg} / \mathrm{Cve}$ & & 1,2 & 1,1 & 0,7 & 0,9 & 2,0 & 2,0 & 1,7 \\
\hline \multicolumn{9}{|l|}{ Testador 2 (AG9010) } \\
\hline Blocos & 1 & 2414361,7 & 46063,6 & 23191,7 & 208445,7 & 0,17 & 0,01 & 7,75 \\
\hline Topcrosses & 46 & $681974,9 *$ & $1599674,9^{*}$ & $3235847,6^{*}$ & $2571762,2^{*}$ & $2,64 *$ & $2,24 *$ & $2,10 *$ \\
\hline Resíduo & 46 & 122210,3 & 406784,3 & 374571,6 & 821993,9 & 0,65 & 0,75 & 0,78 \\
\hline Média & & 3615,6 & 6270,6 & 7060,3 & 7008,8 & 60,4 & 60,8 & 3,9 \\
\hline Média do Híbrido & & 5061,8 & 8465.3 & 9108,4 & 8207,3 & - & - & - \\
\hline Cve & & 9,7 & 10,2 & 8,7 & 12,9 & 1,3 & 1,4 & 22,4 \\
\hline$\hat{\sigma}^{2} f$ & & 340987,4 & 799837,4 & 1617923,8 & 1285881,1 & 1,32 & 1,12 & 1,05 \\
\hline$\hat{\sigma}^{2} g$ & & 279882,2 & 596445,3 & 1430638,0 & 874884,1 & 1,00 & 0,75 & 0,67 \\
\hline$\hat{h}^{2}$ & & 0,82 & 0,75 & 0,88 & 0,68 & 0,75 & 0,67 & 0,63 \\
\hline $\mathrm{CVg}$ & & 14,6 & 12,3 & 16,9 & 13,3 & 1,7 & 1,4 & 20,8 \\
\hline $\mathrm{CVg} / \mathrm{Cve}$ & & 1,5 & 1,2 & 2,0 & 1,0 & 1,2 & 1,0 & 0,9 \\
\hline
\end{tabular}

IBI = Ibirarema, SP; RBR = Rio Brilhante, MS; SMI = São Miguel do Iguaçu, PR; FLO = Floresta, PR. FM = Florescimento Masculino; FF $=$ Florescimento Feminino. DRTR = Resistência ao estresse hídrico (nota de avaliação visual, sendo as menores as mais resistentes). *p < 0,05 ns: $\mathrm{p}>0,05$.

Rev. Ceres, Viçosa, v. 63, n.4, p. 492-501, jul/ago, 2016 
de grãos $\left(\mathrm{kg} \mathrm{ha}^{-1}\right)$ variam para os diferentes experimentos, a saber: 7.116, em Floresta, PR; 6.886, em São Miguel do Iguaçu, PR; 6.244, em Rio Brilhante, MS; e 3648 em Ibirarema, SP (Tabela 3). Isso sugere que as diferentes condições edafoclimáticas tiveram influência sobre esses valores e, consequentemente, sobre as inferências baseadas nas médias dos genótipos. Já o ambiente de Ibirarema, SP, caracterizou-se como de estresse hídrico (Tabela 2), que se reflete na média de rendimento de grãos desse ambiente. Nesse sentido, a variável rendimento de grãos desse ambiente é uma possível medida da tolerância dos topcrosses e, por conseguinte, das linhagens.

A habilidade dos testadores em discriminar a capacidade combinatória das linhagens foi estimada por meio das estimativas de variância genética, de herdabilidade, no sentido amplo, e do coeficiente de variação genética, apresentado nas Tabelas 3 e 4. Para o rendimento de grãos, as maiores estimativas de variância genética, de herdabilidade e de coeficiente de variação genética foram observadas para os topcrosses com o testador AG9010. Nesse sentido, é possível inferir que as diferenças entre linhagens para esta característica foram mais evidentes quando utilizado este testador.

Com relação aos florescimentos feminino e masculino, observando-se os valores de variância genética, de herdabilidade e de coeficiente de variação genética entre topcrosses e per se, é notório que ambos os testadores apresentaram uma tendência de redução de todas as estimativas correlatas à variabilidade genética; indicando que o desempenho dos topcrosses foi, em grande parte, devido ao efeito do testador e, nesse sentido, a avaliação per se mostrou-se, a priori, mais apropriada para determinar o mérito genético das linhagens. O efeito do genótipo testador sob esta característica é grande, requerendo cuidados adicionais na escolha de testadores.
O resumo das análises dialélicas parciais, para as características de rendimento de grãos, de florescimento e de tolerância ao estresse hídrico, são apresentados na Tabela 5. Para todas as características, foram detectadas diferenças significativas $(\mathrm{p}<0,10)$ para capacidade geral de combinação (CGC) das linhagens avaliadas e testadores. Isso indica que uma ou mais linhagens apresentam destacadas estimativas de CGC $\left(\hat{g}_{i}\right)$. Esta situação é considerada favorável ao melhoramento, uma vez que é atestada a possibilidade de seleção entre as linhagens.

Para os testadores, esta significância, observada para rendimento de grãos em São Miguel do Iguaçu, PR e em Floresta, PR, para florescimento e para tolerância ao estresse hídrico, indicou que os testadores diferenciaramse quanto às suas contribuições para os topcrosses, ou seja, as linhagens tiveram diferentes performances quando cruzadas com cada um dos testadores utilizados.

A análise dialélica parcial conjunta, avaliada em diferentes ambientes, permitiu quantificar as capacidades geral e específica de combinações, bem como suas interações com o ambiente. Assim como observado nas análises individuais, na análise dialélica parcial conjunta, a capacidade geral de combinação das linhagens foi significativa ( $\mathrm{p}<$ 0,10 ) para rendimento de grãos (Tabela 6). Ademais, os efeitos da interação CGC (linhagens) x ambientes foram significativos $(\mathrm{p}<0,10)$, denotando a importância dos ambientes na determinação da CGC das linhagens. Para os testadores, as diferenças de CGC foram não significativas ( $\mathrm{p}>0,10$ ) na análise conjunta e a significância de CGC (testadores) $\mathrm{x}$ ambiente $(\mathrm{p}<0,10)$ reforça a importância da interação genótipo $v s$ ambiente e mostra que a utilização de experimentos em vários locais é de fundamental importância para a escolha dos testadores a serem utilizados em programas visando ao desenvolvimento de híbridos para a safrinha.

Tabela 4: Análise de variância e estimativas de parâmetros genéticos e fenotípicos para as características avaliadas nas linhagens per se, em Floresta, PR

\begin{tabular}{|c|c|c|c|c|}
\hline \multirow{3}{*}{ Fontes de variação } & \multirow{3}{*}{ GL } & \multicolumn{3}{|c|}{ Quadrado médio } \\
\hline & & \multirow{2}{*}{$\frac{\text { Rendimento de grãos }}{\left(\mathrm{kg} \mathrm{ha}^{-1}\right)^{2}}$} & \multicolumn{2}{|c|}{ Florescimento } \\
\hline & & & Masculino $(d)^{2}$ & Feminino $(d)^{2}$ \\
\hline Blocos & 1 & 704345,65 & $0,10 \mathrm{~ns}$ & $0,04 \mathrm{~ns}$ \\
\hline Linhagens & 46 & $1422684,66^{*}$ & $35,57 *$ & $44,67 *$ \\
\hline Resíduo & 46 & 555911,36 & 0,44 & 0,48 \\
\hline Média & & 3189,76 & 67,41 & 68,89 \\
\hline Cve & & 23,37 & 0,99 & 1 \\
\hline$\hat{\sigma}^{2} f$ & & 711342,33 & 17,785 & 22,335 \\
\hline$\hat{\sigma}^{2} g$ & & 433386,65 & 17,565 & 22,095 \\
\hline$\hat{h}^{2}$ & & 0,61 & 0,99 & 0,99 \\
\hline $\mathrm{CVg}$ & & 20,6 & 6,2 & 6,8 \\
\hline $\mathrm{CVg} / \mathrm{Cve}$ & & 0,9 & 6,3 & 6,8 \\
\hline
\end{tabular}

$* \mathrm{p}<0,05$ pelo teste F. ns $\mathrm{p}>0,05$ 
As metodologias de avaliação de linhagens, como os topcrosses e os cruzamentos dialélicos, têm grande valia e permitem a melhoria dos processos dispendiosos em tempo e recursos, que envolvam o desenvolvimento de linhagens em programas de melhoramento. Nesse sentido, as linhagens 4, 9, 16, 21, 37, 38, 39 e 47 foram consideradas as mais promissoras dentre as avaliadas neste estudo (Tabela 7). Essas linhagens tiveram estimativas satisfatórias de capacidade geral de combinação para características fundamentais e em condições frequentes nos cultivos de milho safrinha, nas diversas regiões do Brasil.

A linhagem 4, originada do híbrido DKB350, teve favorável para rendimento de grãos nos ambientes de Ibirarema, SP, e Rio Brilhante, MS. Os valores de $\hat{g}_{i}$ para essa mesma variável, em Floresta, PR e São Miguel do Iguaçu, PR e, também, para florescimento e tolerância ao estresse, não diferiram da média do dialelo, sendo positivos ou negativos, todavia sem alcançar o valor de duas vezes o desvio padrão. Nesse sentido, a linhagem 4 parece mostrar-se uma boa opção para ambientes com estresse hídrico, ou média, com alta tecnologia, como em Ibirarema, SP e em Rio Brilhante, MS, respectivamente. Ambientes com essas características são frequentes para cultivos de safrinha. Nesse sentindo, linhagens com essas características são importantes para programas de melhoramento voltados à safrinha.
As linhagens 9 e 16, obtidas de sucessivas autofecundações dos híbridos AG6018 e DKB747, respectivamente, apresentaram $\hat{g}_{i}$ positivos e relevantes para os ambientes de Floresta, PR e São Miguel do Iguaçu, PR. Nesse sentido, essas linhagens caracterizam-se como boa opção para a síntese de híbridos para cultivos de alta tecnologia. Com base nos demais $\hat{g}_{i}$, ainda é possível concluir que híbridos sintetizados pelas linhagens 9 e 16 não receberão, delas, boas contribuições para rendimento, nas condições de média à alta tecnologia ou estresse hídrico. Essa inferência é suportada pelos valores de $\hat{g}_{i}$ irrelevantes nos ambientes de Iberarema, SP e de Rio Brilhante, MS. Ainda assim, essas linhagens não farão contribuições no sentido da precocidade em seus híbridos, sendo, portanto, esperados valores próximos ao da média do dialelo. Essas linhagens podem integrar populações-base para melhoramento, sendo utilizadas em virtude de suas contribuições com possíveis genes de resistência aos estresses da safrinha.

A linhagem 21, originada do híbrido duplo DKB747, foi a mais destacada dentro do conjunto de linhagens envolvidas neste estudo e teve relevantes e positivos valores de $\hat{g}_{i}$ para rendimento de grãos, nos quatro ambientes testados, em condições de estresse hídrico, de média à alta tecnologia e alta tecnologia. Certamente, isso

Tabela 5: Análise dialélica parcial

\begin{tabular}{|c|c|c|c|c|c|c|c|c|}
\hline \multirow{4}{*}{ Fontes de variação } & \multirow{4}{*}{ GL } & \multicolumn{6}{|c|}{ Quadrados médios } & \multirow{4}{*}{$\begin{array}{c}\text { DRTR } \\
\text { IBI }\end{array}$} \\
\hline & & \multirow{2}{*}{\multicolumn{4}{|c|}{$\begin{array}{c}\text { Rendimento de grãos } \\
\left(\mathrm{kg} \mathrm{ha}^{-1}\right) \\
\end{array}$}} & \multicolumn{2}{|c|}{ Florescimento } & \\
\hline & & & & & & FM (d) & FF (d) & \\
\hline & & \multirow{2}{*}{$\frac{\text { IBI }}{608480,7 *}$} & \multirow{2}{*}{$\begin{array}{c}\mathbf{R B R} \\
1382095,2 *\end{array}$} & \multirow{2}{*}{$\frac{\text { SMI }}{2231342,2 *}$} & \multirow{2}{*}{$\frac{\text { FLO }}{1977135,5^{*}}$} & \multicolumn{2}{|c|}{ FLO } & \\
\hline Topcrosses & 93 & & & & & $11,10^{*}$ & $11,00 *$ & $2,74^{*}$ \\
\hline CGC (testadores) & 1 & $205651,7 \mathrm{~ns}$ & $128938,6 \mathrm{~ns}$ & $5697875,1^{*}$ & $2168925,8^{*}$ & $640,47 *$ & $625,79 *$ & $15,50 *$ \\
\hline CGC (linhagens) & 46 & $722691,4^{*}$ & $1314870,7^{*}$ & $2299100,1^{*}$ & $2201715,0 *$ & $6,10^{*}$ & $5,53 *$ & $2,98^{*}$ \\
\hline CEC & 46 & $503027,2 *$ & $1476562,2^{*}$ & $2088225,0^{*}$ & $1748386,6^{*}$ & $2,42^{*}$ & $3,12 *$ & $2,22 *$ \\
\hline Resíduo & 92 & 129389,5 & 379370,0 & 466206,0 & 683073,0 & 0,65 & 11,00 & 0,81 \\
\hline
\end{tabular}

IBI = Ibirarema-SP; RBR = Rio Brilhante-MS; SMI = São Miguel do Iguaçu-PR; FLO = Floresta-PR. FM = Florescimento masculino; FF = Florescimento feminino. DRTR $=$ Resistência ao estresse hídrico (dados de avaliação visual). *p < 0,10 ; ns não significativo $(\mathrm{p}>0,10)$.

Tabela 6: Análise dialélica parcial conjunta para rendimento de grãos

\begin{tabular}{lcc}
\hline Fontes de variação & GL & Quadrado médio \\
\hline Topcrosses & 93 & $3422055,8^{*}$ \\
CGC (testadores) & 1 & $168053,5 \mathrm{~ns}$ \\
CGC (linhagens) & 46 & $3112795,9^{*}$ \\
CEC & 46 & $3802054,9^{*}$ \\
Ambientes & 3 & $477319531,5^{*}$ \\
Topcrosses $\times$ ambientes & 279 & $925666,0^{*}$ \\
CGC (testadores) $\times$ ambientes & 3 & $2677779,2^{*}$ \\
CGC (linhagens) $\times$ ambientes & 138 & $1141860,5^{*}$ \\
CEC $\times$ ambientes & 138 & $671382,0^{*}$ \\
Resíduo combinado & 184 & 414509,625 \\
\hline
\end{tabular}

* p $<0,05$ pelo teste F. ns $\mathrm{p}>0.05$ pelo teste F.

Rev. Ceres, Viçosa, v. 63, n.4, p. 492-501, jul/ago, 2016 
a caracteriza como a linhagem mais promissora, apresentando elevada capacidade geral de combinações aditivas e relevantes para rendimento em seus cruzamentos. Com relação ao florescimento, podem ser esperados valores próximos aos da média geral do dialelo, uma vez que a linhagem não exibiu relevantes estimativas de $\hat{g}_{i}$ para essa característica. Por sua promissora contribuição aditiva em seus híbridos, essa linhagem pode ser indicada para melhoramento de populações, em cruzamentos, por exemplo, com linhagens promissoras e precoces originadas da mesma fonte, inclusive. Essas populações de melhoramento podem ainda ser retrocruzadas para a linhagem 21. Nesse sentido, por meio de seleção, seria possível obter linhagens derivadas dessa linhagem com alta capacidade de combinação e precoces, algo fundamental para a safrinha.

A linhagem 37, originada do híbrido P30F98, apresentou $\hat{g}_{i}$ positivo e relevante para rendimento de grãos na condição de estresse hídrico, em Ibirarema, SP. Pelos valores de $\hat{g}_{i}$ para rendimento, nos demais locais, essa linhagem não apresentou contribuições, negativas ou positivas, quando considerada a média geral do dialelo. Essa inferência é baseada na ausência de $\hat{g}_{i}$ que superassem em, no mínimo, duas vezes o desvio padrão das estimativas de capacidade geral de combinação para cada característica. Em virtude da destacada capacidade geral sob condições de estresse, essa linhagem foi incluída entre as de maior destaque.

Tabela 7: Estimativas de capacidade geral de combinação $\left(\hat{g}_{i}\right)$ das linhagens e estimativas de capacidade específica de combinação $\left(\hat{S}_{i j}\right)$ entre os testadores e as linhagens para as características avaliadas

\begin{tabular}{|c|c|c|c|c|c|c|c|}
\hline \multicolumn{8}{|c|}{ Capacidade geral de combinação $\left(\hat{g}_{i}\right)$ das linhagens } \\
\hline \multirow{3}{*}{ Linhagens } & \multicolumn{4}{|c|}{ Rendimento de grãos $\left(\mathrm{kg} \mathrm{ha}^{-1}\right)$} & \multicolumn{2}{|c|}{ Florescimento } & \multirow{3}{*}{$\begin{array}{c}\text { DRTR } \\
\text { IBI }\end{array}$} \\
\hline & \multirow[t]{2}{*}{ IBI } & \multirow[t]{2}{*}{ RBR } & \multirow[t]{2}{*}{ SMI } & \multirow[t]{2}{*}{ FLO } & FM (d) & FF (d) & \\
\hline & & & & & \multicolumn{2}{|c|}{ FLO } & \\
\hline 4 & 504,13 & 1318,05 & $-516,40$ & $-310,48$ & $-0,46$ & $-0,64$ & $-0,64$ \\
\hline 9 & $-16,68$ & $-235,84$ & 1899,07 & 837,00 & 1,29 & 0,61 & $-0,89$ \\
\hline 16 & $-301,85$ & 229,17 & 998,77 & 1446,95 & 0,04 & $-0,14$ & $-0,14$ \\
\hline 21 & 446,89 & 622,39 & 930,61 & 1028,01 & 1,54 & 1,36 & 1,36 \\
\hline 37 & 732,96 & 154,20 & 394,02 & 674,33 & $-0,46$ & $-0,14$ & $-1,39$ \\
\hline 38 & 436,12 & 520,22 & 759,24 & 770,54 & $-2,21$ & $-1,39$ & 0,86 \\
\hline 39 & 920,96 & 605,86 & $-74,04$ & $-828,80$ & $-0,96$ & $-1,89$ & $-0,39$ \\
\hline 47 & 799,39 & $-279,24$ & $-296,17$ & 148,68 & $-1,46$ & $-0,89$ & $-0,39$ \\
\hline $\mathrm{DP}(\mathrm{gj})$ & 177,93 & 304,67 & 337,74 & 408,82 & 0,40 & 0,42 & 0,44 \\
\hline DP (gj-gj') & 254,35 & 435,53 & 482,81 & 584,41 & 0,57 & 0,61 & 0,63 \\
\hline $2 \times \mathrm{DP}(\mathrm{gj})$ & 355,86 & 609,34 & 675,49 & 817,64 & 0,80 & 0,85 & 0,89 \\
\hline \multicolumn{8}{|c|}{ Capacidade específica de combinação $\left(\hat{S}_{i j}\right)$ entre os testadores e as linhagens } \\
\hline \multirow{3}{*}{ Linhagens } & \multicolumn{4}{|c|}{ Rendimento de grãos $\left(\mathrm{kg} \mathrm{ha}^{-1}\right)$} & \multicolumn{2}{|c|}{ Florescimento } & DRTR \\
\hline & IBI & RBR & SMI & FLO & FM (d) & FF (d) & \\
\hline & & & & & \multicolumn{2}{|c|}{ FLO } & IBI \\
\hline $\mathrm{P} 30 \mathrm{~K} 75 \times 11$ & 436,00 & 866,38 & 533,96 & $\mathbf{1 2 4 8 , 5 6}$ & $-1,35$ & $-1,07$ & $-0,21$ \\
\hline $\mathrm{P} 30 \mathrm{~K} 75 \times 13$ & 384,66 & 1375,77 & 932,63 & 1001,17 & $-1,10$ & $-1,07$ & $-0,21$ \\
\hline $\mathrm{P} 30 \mathrm{~K} 75 \times 14$ & 528,40 & 1455,99 & 380,24 & 708,26 & $-1,10$ & $-0,82$ & 0,04 \\
\hline $\mathrm{P} 30 \mathrm{~K} 75 \times 18$ & 898,87 & 1449,35 & 1762,73 & 1641,01 & 0,15 & 0,18 & $-1,71$ \\
\hline $\mathrm{P} 30 \mathrm{~K} 75 \times 19$ & 465,58 & 749,36 & 1496,74 & 1838,42 & 1,15 & 1,18 & $-0,96$ \\
\hline $\mathrm{P} 30 \mathrm{~K} 75 \times 20$ & 355,06 & 1068,00 & 1807,13 & 844,53 & 0,40 & 0,18 & $-0,46$ \\
\hline $\mathrm{P} 30 \mathrm{~K} 75 \times 22$ & 226,85 & 1123,58 & 1290,41 & 1049,58 & 1,65 & 1,68 & $-1,71$ \\
\hline AG9010 × 35 & 469,90 & 1101,54 & 1054,58 & 461,75 & 0,85 & 0,82 & 0,96 \\
\hline AG9010 × 37 & 487,99 & 1078,62 & 1197,71 & 1075,94 & $-0,90$ & $-0,68$ & $-0,04$ \\
\hline AG9010 × 39 & 447,79 & 603,01 & 226,13 & $-363,97$ & 0,60 & 0,07 & $-1,54$ \\
\hline $\mathrm{DP}(\mathrm{Sij}):$ & 177,93 & 304,67 & 337,75 & 408,82 & 0,40 & 0,42 & 0,44 \\
\hline DP(Sij-Sik) & 254,35 & 435,53 & 482,81 & 584,41 & 0,57 & 0,61 & 0,63 \\
\hline DP(Sij-Skj) & 355,86 & 609,34 & 675,49 & 817,64 & 0,80 & 0,85 & 0,89 \\
\hline DP(Sij-Skl) & 248,88 & 426,16 & 472,42 & 571,84 & 0,56 & 0,59 & 0,62 \\
\hline $2 \times \mathrm{DP}(\mathrm{Sij})$ & 355,86 & 609,34 & 675,49 & 817,64 & 0,80 & 0,85 & 0,89 \\
\hline
\end{tabular}

DP: desvio padrão. Em negrito, estimavas relevantes. IBI= Ibirarema, SP, RBR= Rio Brilhante, MS, SMI= São Miguel do Iguaçu, PR, $\mathrm{FLO}=$ Floresta, $\mathrm{PR}$. 
As linhagens 38, 39 e 47, originadas, respectivamente, dos híbridos DAS422, SPEED e DAS2C599, apresentaram $\hat{g}_{i}$ para rendimento, em dois locais, incluindo o ambiente de estresse hídrico (Ibirarema, SP), e também tiveram $\hat{g}_{i}$ negativos e relevantes para florescimento, indicando a contribuição no sentido da precocidade em seus híbridos. De fato, isso sugere que elas apresentam algum mecanismo fisiológico ou genético de tolerância ao estresse hídrico, em relação às demais deste estudo. Muito embora a linhagem 39 apresentasse $\hat{g}_{i}$ negativo e relevante, em Floresta, PR, essas linhagens foram incluídas entre as destacadas quanto à capacidade geral de combinação para rendimento, nas condições supracitadas, e para florescimento.

Uma vez que os testadores utilizados são híbridos comerciais, a utilização de seus cruzamentos com as linhagens não apresenta utilidade agronômica e comercial, mas fundamenta-se na identificação de linhagens adaptadas às condições de safrinha. Porém, combinações favoráveis podem ainda ser aproveitadas para fins de melhoramento. Nesse sentido, considerando-se apenas os cruzamentos com as linhagens promissoras $(4,9,16,21,37,38,39$ e 47$)$, apenas o cruzamento AG9010 x linhagem 37 teve estimativas relevantes de capacidade específica de combinação para rendimento de grãos e também para florescimento feminino. Assim, esta combinação indica apreciável informação para o melhoramento. A linhagem 37 é o melhor testador de novas linhagens extraídas do testador AG9010 (Tabela 7). Com o testador P30K75 destacou-se o cruzamento com a linhagem 18 (Tabela 7). Nesse contexto, essa linhagem é o melhor testador das novas linhagens oriundas do híbrido P30K75. As médias observadas para rendimento confirmam e dimensionam esta heterose destacada e suportam essa recomendação. Foram observados, para a combinação AG9010 x linhagem $37\left(8759 \mathrm{~kg} \mathrm{ha}^{-1}\right.$, em Floresta, PR, rendimentos de $8652 \mathrm{~kg} \mathrm{ha}^{-1}$; em São Miguel do Iguaçu, PR, de $7503 \mathrm{~kg} \mathrm{ha}^{-1}$, em Rio Brilhante, MS, e de $4837 \mathrm{~kg} \mathrm{ha}^{-1}$, em Ibirarema, SP).

Ainda por meio das estimativas de capacidade específica de combinação, é possível inferir sob a base genética dos testadores. Nesse sentido, com o testador 1 (P30K75) destacaram-se as linhagens 11, 13, 14, 18, 19, 20 e 22 e, com o testador 2 (AG9010), os maiores destaques foram os cruzamentos com as linhagens 35, 37 e 39 (Tabela 7). Segundo Clovis et al., (2015), esses resultados suportam a hipótese de que os testadores têm bases genéticas divergentes e que esses cruzamentos são provenientes de grupos heteróticos distintos, o que é comprovado com os altos rendimentos obtidos com ambos os testadores, quando comparados com os rendimentos das linhagens per se.

O testador AG9010 (Agroceres) mostrou alta heterose com as linhagens vindas dos híbridos comerciais 30F33 (Pioneer), 30F98 (Pioneer), DAS422 (Dow Agroscience) e SPEED (Syngenta), todos híbridos de empresas diferentes da que desenvolveu o híbrido utilizado como testador. No mesmo sentido, o testador P30K75 (Pioneer) teve alta heterose com as linhagens 11,12, 13, 14, 18, 19, 20 e 22 (Tabela 7), todas provenientes do híbrido DKB747 (Dekalb).

Via topcross avaliam-se os valores genéticos (breeding values) das linhagens, o que não acontece com a avaliação per se. Por meio desses topcrosses, é prudente afirmar que a variância genética das linhagens supera a variância residual dos experimentos, sendo que, desta forma, a seleção é facilitada e ganha em confiabilidade.

Com o testador P30K75, destacaram-se os topcrosses com as linhagens 11, 13, 14, 18, 19, 20 e 22 (Tabela 7). Já com o testador AG9010, os maiores destaques foram os cruzamentos com as linhagens 35, 37 e 39 (Tabela 7). Esses resultados indicam que os testadores têm bases genéticas diferentes, o que explica a capacidade específica de combinação (CEC) dos testadores com dois grupos de linhagens. As linhagens que obtiveram destaque na análise da CEC com o testador 1 (P30K75) são originadas de híbridos de Empresas diferentes daquela do testador. Da mesma forma, as linhagens que obtiveram destaque quando cruzadas com o testador 2 (AG9010) também são provenientes de híbridos de Empresa diferente daquela do testador. Isso leva a conclusão de que esses cruzamentos são provenientes de grupos heteróticos distintos, por explorarem a heterose, que é comprovada com o alto rendimento obtido com ambos testadores, quando comparados com o rendimento das linhagens per se.

\section{CONCLUSÕES}

A linhagem 21 mostrou alta capacidade geral de combinação para rendimento de grãos nos quatro ambientes, sendo apropriada para melhoramento de populações por sua estabilidade.

As linhagens 4, 38, 39 e 47 foram destacadas por apresentarem capacidade geral de combinação favorável para rendimento de grãos sob condições de estresse hídrico. Já as linhagens 38,39 e 47 tiveram destaque por apresentarem capacidade geral de combinação favorável para rendimento em mais de um local e para florescimento precoce.

As combinações AG9010 x 37 e P30K75 x 18 revelaram capacidades específicas de combinação destacadas para as características estudadas. Essas linhagens foram indicadas como testadoras para novas linhagens oriundas dos próprios testadores.

\section{REFERÊNCIAS}

Amorim EP \& Souza JC (2005) Híbridos de milho inter e intrapopulacionais obtidos a partir de populações $\mathrm{S}_{0}$ de híbridos simples comerciais. Bragantia, 64:561-567.

Banziger M, Edmeades GO, Beck D \& Bellon M (2000) Breeding for Drought and Nitrogen Stress Tolerance in Maize: From Theory to Practice. México, CIMMYT. p.68-81. 
Bison O, Ramalho MAP \& Raposo FV (2003) Potencial de híbridos simples de milho para extração de linhagens. Ciência e Agrotecnologia, 27:348-355.

Casagrande JRR \& Fornasieri Filho D (2002) Adubação nitrogenada na cultura do milho safrinha. Pesquisa Agropecuária Brasileira, 37:33-40.

Cruz CD (2013) GENES - a software package for analysis in experimental statistics and quantitative genetics. Acta Scientiarum. Agronomy, 35:271-276.

Clovis LR, Scapim CA, Pinto RJB, Bolson E \& Senhorinho HJC (2015) Avaliação de linhagens S3 de milho por meio de testadores adaptados à Safrinha. Revista Caatinga, 28:109-120.

Davis RL (1927) Report of the plant breeder. Rio Piedras, Puerto Rico Experimental Estation. p.14-15.

Geraldi IO \& Miranda Filho JB (1988) Adapted models for the analysis of combining ability of varieties in partial diallel crosses. Brazilian Journal of Genetics, 2:419-430.

Gomes FP (1982) Curso de Estatística Experimental. Piracicaba, Atual. 440p.

Griffing AR (1956) Concept of general and specific combining ability in relation to diallel crossing system. Australian Journal of Biological Science, 9:463-493.

Hallauer AR (1975) Relation of gene action type of tester in maize breeding procedures. Proceeding Annual Corn Sorghum Research Conference, 30:150-165.

Kvitschal MV, Scapim CA, Tonet A, Pinto RJB, Retuci VS, Amaral Junior AT \& Braccini AL (2004) Análise dialélica de populações de milho na região noroeste do Paraná, na safrinha. Revista Ceres, 51:19-32.
Kolmogorov-Smirnov AN (1933) Sulla determinazione empírica di uma legge di distribuzione. Giornale dell'Istituto degli Attuari, 4:83-91.

Levene H (1960) Robust tests for equality of variances. In: Olkin I, Ghurye SG, Hoeffding W, Madow WG \& Mann HB (Eds.) Contributions to Probability and Statistics: Essays in Honor of Harold Hotelling. Menlo Park, Stanford University Press. p.278-292.

Mugo SN, Edmeades GO \& Kirubi DT (2003) Genetic improvement for drought tolerance to high plant density in tropical maize under low input levels. International Symposium on Plant Breeding, México. Book of Abstracts, CIMMYT. p.17-22.

Penariol FG, Fornasieri FD, Coicev L, Bordin L \& Farinelli R (2010) Comportamento de cultivares de milho semeadas em diferentes espaçamentos entre linhas e densidades populacionais, na safrinha. Revista Brasileira de Milho e Sorgo, 2:52-60.

Scapim CA, Carvalho CGP \& Cruz CD (1995) Uma proposta de classificação dos coeficientes de variação para a cultura do mi1ho. Pesquisa Agropecuária Brasileira, 30:683-686.

Silveira FT \& Moro JR (2009) Utilização de linhagens parcialmente endogâmicas S3 para a obtenção de híbridos simples de milho. Revista Biociências, 15:10-14.

Souza EFC \& Soratto RP (2006) Efeito de fontes de nitrogênio em cobertura, no milho safrinha, em plantio direto. Revista Brasileira de Milho e Sorgo, 5:395-405. 